\title{
Teoría de la modernidad y experiencia moderna del tiempo en Habermas
}

\author{
José Manuel Romero \\ Universidad de Granada
}

RESUMEN: El objetivo del presente trabajo es mostrar cómo, a partir de los abordajes teóricos de autores situados en momentos distantes del desarrollo de la sociedad moderna, como Hegel y Habermas, pueden ponerse de manifiesto las paradojas planteadas por Walter Benjamin: la modernidad es un modelo que adopta como normativo el tipo de desarrollo ya efectuado por determinadas sociedades del planeta. En este escrito se discutirá con la teoría de la modernización de Habermas.

ABSTRACT: The following essay aims to show how, from the theoretical approaches by two authors, located in distant moments of the development of the modern society, as Hegel and Habermas, the paradoxes of Modernity posed by Walter Benjamin become evident: modernity is a model that assumes as normative the kind of development of certain societies in the planet. In this writing the modernization theory of Habermas will be discussed. 
E n su intento de hacer verosímil el pensamiento del eterno retorno, Nietzsche recurrió en sus notas póstumas a un argumento que recuerda a las formas de especulación presocrática: si el tiempo es algo que carece de comienzo, debe suponerse entonces que "hasta este instante ha transcurrido ya una eternidad", lo cual implica que "todos los desarrollos posibles tienen que haber existido ya"1. La afirmación del carácter infinito del tiempo transcurrido hasta ahora exige concluir que toda posibilidad cualitativamente nueva tiene que haberse dado ya en el pasado: "Si no todas las posibilidades en el orden y relación de las fuerzas se hubieran ya agotado, no habría transcurrido aún ninguna infinitud: porque eso debe haber ocurrido, no existe ninguna nueva posibilidad más y todo debe ya haber sido, incontables veces."2 Esta tesis ontológica que afirma la absolutez de una inmanencia que cierra la emergencia de toda nueva posibilidad parece contraponerse a la esencia de la modernidad y ha sido considerada como una prueba del antimodernismo de Nietzsche: como un retorno de lo antiguo precisamente en el momento en que se está empezando a tematizar de forma reflexiva la noción de modernidad, tal como muestran las reflexiones casi coetáneas de Baudelaire.

Sin embargo, tal tajante contraposición entre retorno de lo igual y modernidad puede ser suavizada a partir de las reflexiones de Walter Benjamin sobre la época moderna, realizadas en el marco de un cuestionamiento filosófico y político de la categoría burguesa de progreso. Benjamin, sin caer en una simple identificación entre modernidad y eterno retorno, descubre en la dinámica profunda de aquélla una peculiar dialéctica entre lo nuevo y lo siempre igual que la define como época del infierno: "Definición de la "modernidad" como lo nuevo en el contexto de lo que ya siempre ha sido. (...) La modernidad es la época del infierno. Las penas del infierno son lo novísimo que en cada momento hay en este terreno. No se trata de que ocurra "siempre otra vez lo mismo" (a forteriori no se trata aquí del eterno retorno), sino de que la faz del mundo, la inmensa cabe$z a$, precisamente en aquello que es lo novísimo, jamás se altera, se trata de que esto "novísimo" permanece siendo de todo punto siempre lo mismo. Esto constituye la eternidad del infierno y el afán innovador del sádico. Determinar la totalidad de los rasgos en los que se manifiesta la "modernidad" significaría exponer el infierno." ${ }^{3}$ Esta mutua implicación de lo nuevo y lo siempre igual es descifrada por Benjamin en ese fenómeno originario (lo que en la teoría de la naturaleza de Goethe se denominaba Urphänomen) de la sociedad moderna que es la mercancía, en la cual la presunción de novedad no es más que una máscara tras la que retornan una y otra vez las mismas relaciones de producción. Tal forma de temporalidad es lo que para el autor berlinés define como tal a la modernidad 
y constituye la esencia catastrófica del progreso burgués.

La aparente radicalidad del diagnóstico de Benjamin no debe inducir a un apresurado rechazo de las razones de este idiosincrático pensador. Pues a pesar de su formulación quizá críptica, sus reflexiones e iluminaciones logran tematizar lo que puede considerarse una importante paradoja del proceso de modernización tal como realmente ha acontecido y tal como ha sido teorizado por importantes fundamentaciones filosóficas de la modernidad. El objetivo del presente trabajo es mostrar cómo a partir de las teorizaciones de la modernidad de relevantes justificadores filosóficos de la misma, situados en momentos distantes del desarrollo de la sociedad moderna, como Hegel y Habermas, puede ponerse de manifiesto la paradoja apuntada por Benjamin. Tal paradoja se va a arraigar en el modelo de modernidad que aquellos autores en líneas generales comparten: un modelo que adopta como normativo para establecer el canon de lo moderno el tipo de desarrollo institucional y socio-económico ya efectuado por determinadas sociedades del planeta. En este escrito voy a ocuparme sobre todo en definir los parámetros para una discusión con la teoría de la modernización de Habermas. Como paso previo realizaré una breve incursión en la concepción de la sociedad moderna de Hegel para mostrar cómo en su teoría del Estado asume un modelo de sociedad sustentado en una concepción de la sociedad civil, con unos caracteres muy precisos, que obstaculiza en su planteamiento la capacidad para percibir la emergencia de posibilidades históricas cualitativamente nuevas e implica el desenvolvimiento de una forma de temporalidad dominada por la repetición de los antagonismos y su culminación en el conflicto bélico internacional (1). A continuación llevaré a cabo una aproximación crítica a la teoría de la modernización de Habermas, donde pondré de manifiesto el modo en que las categorías con las que se pretende aprehender el proceso de modernización social han incorporado ya como normativo un tipo de decurso histórico geopolíticamente ubicable, lo cual va a poseer consecuencias palpables tanto en el alcance crítico de tal teoría como en el plano de la concepción y experiencia del tiempo en las diferentes posiciones del mundo moderno (2).

\section{Hegel y los antagonismos de la sociedad moderna}

— la filosofía del derecho de
Hegel puede encontrarse una
concepción de la sociedad moderna que resulta prototípica del modo de concebir la modernidad por parte de importantes teóricos de 
los siglos XIX y XX: como un proceso evolutivo caracterizable por un patrón unitario que ha alcanzado ya adecuada plasmación en los países del centro de la economía del mundo. Es este modelo de comprensión de la modernidad el que lleva consigo significativas paradojas y el que conduce a consecuencias imprevistas en la dimensión de la experiencia de la temporalidad en el seno de la modernidad realizada.

Juega un papel central en la concepción de la sociedad moderna de Hegel la introducción de la categoría de sociedad civil como espacio definido por el despliegue de la libertad de "la particularidad subjetiva", la cual "se convierte en el principio vivificante de la sociedad civil, del desarrollo de la actividad pensante, del mérito y del honor." ${ }^{4}$ La sociedad civil está constituida por la independencia de la particularidad y por la diferenciación de la libertad subjetiva. Es el espacio de encuentro entre las particularidades orientadas por su interés subjetivo, lo cual determina que "en la sociedad civil cada uno es fin para sí mismo y todos los demás no son nada para él." ${ }^{\prime 5}$ La búsqueda del propio interés por parte de cada particularidad es, piensa Hegel, vivificante de la sociedad civil y, en un marco de división del trabajo, un principio que acrecienta la acumulación de riquezas. Ahora bien, si la plasmación en la sociedad civil de la independización de la particularidad y de la libertad subjetiva es fundamental para la articulación de un Estado propiamente moderno (y lo que lo diferencia de las formas previas de Estado), Hegel es claramente consciente de los efectos socialmente desestructurantes que posee el individualismo económico, pues con la acumulación creciente de riquezas "se acrecienta también la singularización y limitación del trabajo particular, y con ello la dependencia y miseria de la clase ligada a ese trabajo" ${ }^{\prime \prime}$.

La paradoja del principio de la particularidad es que el crecimiento de las riquezas que genera se acompaña de "la caída de una gran masa por debajo de un cierto nivel mínimo de subsistencia"7 ${ }^{\prime \prime}$ El peligro de explosividad social que se deriva de esta situación convierte a "la cuestión de cómo remediar la pobreza" en "un problema que mueve y atormenta a las sociedades modernas." ${ }^{8}$ $Y$ tales sociedades parecen encontrarse aquí ante un dilema irresoluble. Pues proponer la asistencia a los necesitados, financiada por los más ricos, que les proporcione los bienes necesarios para subsistir "sin la mediación del trabajo (...) estaría contra el principio de la sociedad civil y del sentimiento de independencia y honor de sus individuos. Si, por el contrario, esto se hiciera por medio del trabajo (dando oportunidades para ello), se acrecentaría la producción, en cuyo exceso, unido a la carencia de consumidores correspondientes, que también serían productores, reside precisamente el mal, que aumentaría por lo tanto de las dos maneras. Se manifiesta aquí 
que en medio del exceso de riqueza la sociedad civil no es suficientemente rica, es decir, no posee bienes propios suficientes para impedir el exceso de pobreza" ${ }^{\prime \prime}$.

Hegel tematiza aquí la contradicción básica de la economía liberal: la imposibilidad de incorporar en el sistema productivo al conjunto de la población activa ante el peligro de un exceso de producción que conduciría a crisis económicas de peores efectos que la existencia misma de la miseria. Por ello, ante la incapacidad para mejorar las condiciones de vida de la plebe sin atentar contra los principios de la sociedad civil, "el medio más directo que se ha ensayado (...) contra la pobreza (...) ha consistido en abandonar a los pobres a su destino y condenarlos a la mendicidad pública." ${ }^{10}$ Hegel ve así la condición esencial del capitalismo liberal en que éste dispone de una capacidad sin precedentes históricos de generar y acumular riqueza que se ve frenada por la emergencia, necesaria en términos estructurales, de una masa de desempleados y de población precarizada económicamente que no puede integrar en las estructuras del aparato productivo sin poner en peligro las condiciones de su propio crecimiento y reproducción.

Tenemos aquí la dialéctica inmanente de la sociedad civil moderna, una dialéctica que, piensa Hegel, lleva a la sociedad civil más allá de sí. Ahora bien, esta transcendencia respecto a sí no debe ser entendida en términos históricos, en el sentido de que tal dialéctica vaya generando en el seno de la sociedad civil definida por el antagonismo entre las libertades particulares las condiciones para la emergencia histórica de una nueva figura del espíritu en la que tales antagonismos queden superados (aunque surjan otros nuevos). Al constituir la sociedad civil conceptuada por Hegel la forma propia de la sociedad moderna, tales antagonismos son concebidos como irresolubles. Ni siquiera la intervención del Estado modifica esta situación. Hegel sostiene que en la sociedad civil lo universal se ha independizado del individuo orientado únicamente por finalidades e intereses particulares y es algo externo a su particularidad y ello a pesar de que el individuo viva lo universal como algo interior y formal, como es el caso del deber moral kantiano. Esta independización significa que la creencia del individuo de que lo determinante en su acción social es su interés particular es mera apariencia, pues en su autoafirmación como ser particular, al orientarse únicamente por sus propios intereses, lo que se impone en la acción individual es lo universal, que sigue siendo "lo primero y esencial"11. En la búsqueda de cada individuo de la satisfacción de su interés particular no se realiza tal fin intencionado, pues en la confrontación resultante en el ámbito de la sociedad civil lo que se impone como una necesidad externa y no querida es lo universal, que conserva su poder por encima de los individuos. 
En contraste con esta situación, en el seno del Estado lo universal es sabido y querido por los individuos, y no por mero deber, como sostendría un planteamiento de tipo abstracto, sino porque se comprende que el cumplimiento de los deberes respecto al Estado corresponde al interés propio de los ciudadanos ${ }^{12}$. Lo que establece la mediación entre el interés particular (sobre el que se sostiene la sociedad civil) y el interés general (plasmado en el Estado) son las corporaciones, las cuales son agrupaciones de las diferentes ramas profesionales (algo parecido a una versión moderna de los gremios profesionales). A través de la corporación el interés particular llega a identificarse con lo universal, en el sentido de que el individuo alcanza a comprender que es el cumplimiento de sus deberes con lo universal lo que mejor favorece sus intereses particulares ${ }^{13}$. El Estado es así lo universal sabido y querido por el individuo, la realización de su libertad concreta ${ }^{14}$. El Estado y sus instituciones encarnan la realización de lo universal de los intereses particulares de los individuos, por lo que el individuo reflexivo comprende que en el cumplimiento de sus deberes respecto a tales instituciones está satisfaciendo sus intereses más propios. Por ello el nivel de conciliación superior que es el Estado no llega a ser una auténtica reconciliación, pues el Estado deja la dimensión de los antagonismos entre los intereses particulares tal como está. Lo que hace el Estado con el principio moderno de la sub- jetividad es dejar que se consuma "hasta llegar al extremo independiente de la particularidad personal, para al mismo tiempo retrotraerlo a su unidad sustancial, conservando así a ésta en aquél principio mismo"15. El Estado se presenta así como síntesis entre lo singular y lo universal, pero visiblemente se trata de una pseudosíntesis, pues el individuo se sigue moviendo en el seno del Estado orientado por su interés particular, sólo que comprende que el cumplimiento de sus deberes con el Estado es para él provechoso y apropiado según el criterio de su propio interés. No existe una ruptura entre las motivaciones de la acción de los individuos cuando estos actúan en el marco de la sociedad civil o respecto al Estado. La satisfacción de su interés particular es en todos los casos el impulso orientador de la acción. Por ello la constatación colectiva de que cumplir con los deberes de cada uno en relación al Estado (por ejemplo, el pago de impuestos, el cumplimiento de la ley y de los contratos, la sumisión política) corresponde al interés particular de cada cual no cambiaría un ápice la confrontación de las diversas libertades particulares en la que se consiste la sustancia de la sociedad civil.

En tanto que en el modelo social de Hegel resulta irrepresentable una conciliación de los antagonismos sociales tal como están definidos en la sociedad civil moderna, ante el peligro de desestructuración social derivado de los mismos sólo cabe pensar en una relajación de los an- 
tagonismos hasta límites socialmente no explosivos, lo cual es posibilitado por aquella dialéctica propia de la sociedad civil que mencionábamos arriba. Ésta apunta en una dirección en principio insospechada y permite valorar la teoría de la sociedad moderna de Hegel como paradigmática del tipo de teorías de la modernidad que adoptan como perspectiva normativa el marco geopolítico europeo: "Por medio de esta dialéctica suya la sociedad civil es Ilevada más allá de sí; en primer lugar más allá de esta determinada sociedad, para buscar en el exterior consumidores y por lo tanto necesarios medios de subsistencia en otros pueblos que están atrasados respecto de los medios que ella tiene en exceso o respecto de la industria en general. (...) Esta ampliación de las relaciones ofrece también el recurso de la colonización, a la cual —en forma esporádica o sistemáticatiende la sociedad civil avanzada. Por su intermedio la sociedad proporciona a una parte de su población un retorno al principio familiar en otra tierra, y se da a sí misma una nueva demanda y un nuevo campo para su trabajo." ${ }^{16}$ La necesidad de crecimiento y expansión de la economía de mercado conduce a la búsqueda de nuevos mercados en la periferia no industrializada. La desesperación de las masas desempleadas y depauperadas las impulsa a una dinámica de emigración, apoyada por el Estado, como colonos hacia las zonas de expansión territorial de la metrópoli. Este doble proceso permite al mismo tiempo ampliar la producción y disminuir significativamente la bolsa de desposeídos dentro de las fronteras del centro industrial, sin provocar una fatídica crisis de superproducción ni generar espacios dentro de la sociedad en los que la satisfacción de las necesidades no se somete a los principios de reproducción de la sociedad civil burguesa. Pero esta solución es sólo aparente. Pues son varias las economías del centro capitalista las que se ven embarcadas en este doble proceso de conquista de nuevos mercados y de colonización de nuevos territorios en el espacio definido por la superficie finita del globo, lo cual va a establecer las condiciones para un nuevo antagonismo, esta vez internacional y de consecuencias más mortíferas que el primero. La competición feroz entre los diferentes centros productivos nacionales por los limitados mercados existentes en los que volcar su producción excedente y por los territorios en los que poder desprenderse de parte de las masas desempleadas políticamente problemáticas define la relación de los estados entre sí como un "estado de naturaleza"17 y fundamenta el carácter inextricable de la guerra internacional para el mundo moderno, en la cual Hegel quiere descubrir virtudes éticas ${ }^{18}$. Esta conclusión ilumina el planteamiento hegeliano sobre la modernidad con una nueva luz: una vez que el cambio histórico cualitativo ha llegado a su fin en el mundo moderno europeo 
y con él la posibilidad de progreso cualitativo, el decurso de la historia toma la forma de un retorno de la guerra entre las naciones del centro de la economía mundo en pos de unos mercados y unos territorios alarmantemente limitados. Frente a los que peroran contra los conflictos bélicos aferrándose a unas posesiones que no quieren ver en peligro, Hegel defiende la necesidad del glorioso retorno de la guerra: "Los campos [de batalla] vuelven a florecer y las habladurías enmudecen ante la seriedad de las repeticiones de la historia." ${ }^{19}$

El horizonte del mundo moderno es por fin en Hegel el de la absoluta inmanencia, el de la detención de la temporalidad histórica. Se piensa sólo un movimiento de transcendencia espacial de los centros industrializados en la forma de búsqueda de nuevos mercados y territorios en la periferia colonizable, pero esta transcendencia posee evidendemente el límite de la extensión de la superficie terrestre y su fin es por lo tanto anticipable. La irresolubilidad de los antagonismos sociales internos y su exportación hacia el exterior (hacia los países menos desarrollados vinculados asimétricamente con la potencia productora del centro y hacia el ámbito de las relaciones entre las diversas potencias industriales) define la signatura de la temporalidad histórica moderna derivable del esquema histórico hegeliano: una temporalidad que consagra la detención de la historicidad genuina generadora de posibilidades cualitativamente nuevas y el eterno retorno de los antagonismos y de las guerras en los que estos culminan ${ }^{20}$.

Puede plantearse la cuestión de si cabe hablar en Hegel de una paradoja o una tragedia de la libertad moderna de la particularidad y su plasmación como sociedad civil. Pues, por un lado, la libertad de la particularidad genera cotas de prosperidad material sin precedentes $y$ es la condición de posibilidad del Estado moderno y su pretendida síntesis entre lo universal y lo singular. Pero tal libertad genera a su vez todo un cúmulo de antagonismos sociales y efectos de desestructuración social en el seno de las sociedades nacionales que como tales son irresolubles y sólo pueden ser limitados en su alcance (hasta cotas no explosivas) exportando tales antagonismos y efectos desestructurantes al exterior, a la periferia no capitalista y a la relación entre los centros industriales nacionales. La paradoja de la libertad moderna de la particularidad consiste en que su plasmación social (que resulta necesaria y condición de posibilidad del Estado moderno) define el mundo moderno como reino de antagonismos (internos a las sociedades y entre las naciones) no solamente irresolubles, sino generadores de una dinámica de continuo retorno del conflicto en sus diferentes formas, culminando en la para Hegel gloriosa repetición de la guerra. La modernidad es así en Hegel el mundo dominado por los antagonismos 
entre individuos, clases y naciones, antagonismos incapaces de abrir el horizonte de posibilidades históricas cualitativamente nuevas y cuya tendencia apunta a su agudización a medida que se alcanza el límite de la integración de todos los mercados y territorios existentes en el planeta a la economía-mundo capitalista. La inmanencia temporal y la amenazante inmanencia espacial hacen de la modernidad, tal como es conceptuada por Hegel, el mundo dominado por la repetición de lo igual, lo que a los ojos de Benjamin le hace merecer la calificación de infierno.

\section{Habermas y la paradoja de la modernización}

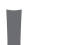

a tesis que voy a defender aquí es que la teoría de la modernidad y de la modernización social de Habermas comparte aspectos relevantes con el modelo de Hegel, a saber, la defensa de un patrón normativo de modernización que coincide con el desplegado en los países occidentales desarrollados. Como en Hegel, las categorías con las que se expone normativamente el proceso de emergencia y constitución de la sociedad moderna son configuradas a partir de un referente histórico concreto, el de determinadas regiones del globo, con lo que se consagra dicho decurso histórico como normativo para toda sociedad que quiera emprender la senda moderna. Esta transfiguración de los procesos históricos específicos de ciertas regiones del globo en normativos, además de conferirles una validez que los blinda respecto a toda crítica, va a poseer consecuencias relevantes y diferenciales para la concepción y la experiencia del tiempo en las diversas posiciones del mundo diferencialmente modernizado.

\subsection{Racionalización y diferen- ciación sistémica}

Amparándose en las ideas de Max Weber, Talcott Parsons y Niklas Luhmann, Habermas concibe el proceso de modernización como un proceso de diferenciación que se lleva a cabo en dos planos. En el plano cultural, la sociedad moderna se caracteriza por la diferenciación de tres esferas de validez autónoma (ciencia, ética posreligiosa y arte secularizado), reguladas cada una de ellas por una pretensión específica de validez discursiva (verdad, corrección según normas y veracidad de la expresión subjetiva $)^{21}$. En el plano social, la modernización consiste en el proceso de institucionalización de la acción racional con respecto a fines en forma de subsistemas (la economía de mercado y la administración estatal) regulados por determinados imperativos funcionales vinculados a las necesidades de reproducción material de las sociedades complejas $^{22}$. Voy a centrarme en esta segunda dimensión, tanto por razones de espacio como por su significado 
teórico y político, enfatizado por el propio Habermas ${ }^{23}$.

El punto de partida de Habermas es la distinción analítica entre dos tipos heterogéneos de integración de la acción en la sociedad y dos formas correspondientes de coordinación de la acción, distinción que considera validada a partir de una teoría de la evolución social que da cuenta de la formación de las sociedades modernas. Para Habermas la condición del surgimiento de tales sociedades es una racionalización del mundo de la vida, consistente en una diferenciación de sus componentes estructurales, es decir, en la diferenciación de los ámbitos de la cultura, la sociedad y la personalidad en el seno del proceso de reproducción simbólica del mundo de la vida, los cuales quedan sometidos a una formalización creciente que relativiza el peso de los contenidos y contextos tradicionales. La racionalización del mundo de la vida tiene lugar a medida que "el lenguaje asume las funciones de entendimiento, de coordinación de la acción y de socialización de los individuos, convirtiéndose con ello en el medio a través del cual se efectúan la reproducción cultural, la integración social y la socialización." 24 Tal racionalización conduce a una generalización de los valores, es decir, a una desvinculación de las orientaciones valorativas respecto de posiciones particularistas representadas por la religión o por tradiciones no penetradas por la reflexión. Esta es la condición de posibilidad histórica de la institucionalización de la acción racional respecto a fines en lo que Habermas denomina plexos funcionales no normativos, es decir, en sistemas regulados no por el entendimiento intersubjetivo, no por valores consensuados, sino por imperativos funcionales inmanentes a dichos sistemas. El impulso para ese proceso de diferenciación sistémica proviene de la tendencia a la complejización que define la emergencia de las sociedades modernas. A partir de un determinado nivel de complejidad social, la coordinación de la acción no puede efectuarse adecuadamente y sin riesgos mediante el entendimiento lingüístico (que es la forma de coordinación de la acción propia del mundo de la vida) sino que exige una forma de coordinación liberada de los costes $y$ de los peligros de aquella ${ }^{25}$. Se trata de una coordinación no normativa a través de estructuras funcionales que implican un modo de integración superior que la anterior al responder adecuadamente a los retos de organización del nuevo nivel de complejización social: "Sobre la base de unas orientaciones de acción cada vez más generalizadas se teje una red cada vez más tupida de interacciones que escapan a un control normativo directo y que tienen que ser coordinadas por otras vías. Para satisfacer esta creciente necesidad de coordinación puede echarse mano, o bien del entendimiento lingüístico, o bien de mecanismos de descarga que reducen 
las expensas en comunicación y los riesgos de disentimiento." ${ }^{26}$ Los mecanismos de coordinación funcional de la acción satisfacen adecuadamente estos criterios, por lo que puede sostener Habermas que "los subsistemas diferenciados a través de los medios dinero y poder posibilitan, frente a las sociedades de clases estatalmente organizadas, un nivel más alto de integración" ${ }^{27}$

El proceso de modernización social consiste pues en la diferenciación de dos subsistemas, la economía de mercado y la administración estatal, que sustituyen como medio de coordinación de la acción al entendimiento lingüístico por dos medios deslingüistizados: el dinero y el poder. Esta diferenciación es exigida por el aumento de la complejidad inherente a las sociedades desarrolladas en los albores de la modernidad y es por tanto necesaria para la reproducción y estabilización de las sociedades modernas, en tanto que constituye su infraestructura funcional: "con independencia de los efectos laterales destructivos anejos al violento proceso de acumulación y de formación de los Estados nacionales, las nuevas formas de organización, merced a la mayor efectividad del superior nivel de integración que representan, desarrollan una gran capacidad de implantación y pervivencia. La forma de producción capitalista y la dominación legal burocrática pueden cumplir mejor las tareas de reproducción material del mundo de la vida (en lenguaje de Parsons: las funciones de adaptación y consecución de fines) que las instituciones feudales o las instituciones del Estado estamental, que les precedieron." ${ }^{28}$ Ahora bien, en contraste con Parsons y Luhmann, la teoría de la modernización de Habermas pretende ser crítica, pero dado que ello no puede implicar en su planteamiento un cuestionamiento del proceso de diferenciación sistémica, el alcance crítico de su teoría se limita a problematizar lo que denomina colonización del mundo de la vida por parte de los sistemas, consistente en la sustitución del medio del entendimiento intersubjetivo por los medios dinero y poder en aquellos ámbitos del mundo de la vida que requieren para su adecuada reproducción del entendimiento lingüístico. Tal colonización se produce cuando "los mecanismos sistémicos acaban desplazando las formas de integración social, incluso en aquellos ámbitos en que la coordinación de la acción en términos de consenso no tiene sustitución alguna, es decir, incluso allí donde lo que está en juego es la reproducción simbólica del mundo de la vida." ${ }^{29}$ Esta sustitución genera patologías diversas en el mundo de la vida ya diagnosticadas por Weber, como la anomia y la pérdida de sentido.

Este proceso de colonización no es constitutivo de la modernización como tal, sino del patrón selectivo $^{30}$ de modernización y de la "racionalización unilateral" ${ }^{11}$ que han seguido de hecho las socieda- 
des capitalistas desarrolladas: "la progresiva desconexión de sistema y mundo de la vida es condición necesaria para el tránsito desde las sociedades de clases estratificadas del feudalismo europeo a las sociedades de clases económicas de la modernidad temprana; empero, el patrón capitalista de modernización se caracteriza porque las estructuras simbólicas del mundo de la vida quedan deformadas, esto es, quedan cosificadas bajo los imperativos de los subsistemas diferenciados y autonomizados a través de los medios dinero y poder." 32 Para Habermas la causa de la colonización del mundo de la vida no reside en la autonomización de la economía capitalista y de la administración estatal respecto al mundo de la vida (su crítica no apunta a lo que podríamos denominar procesos de reificación característicos de la modernidad), sino en el hecho de que "la diferenciación de los subsistemas de acción económica y administrativa se dispara más allá de los límites de la institucionalización del dinero y del poder funcionalmente necesaria en las sociedades modernas", impulsados por "una incontenible dinámica propia"33. Para explicar qué desencadena el modo específico de modernización realmente efectuado en las sociedades desarrolladas considera Habermas que se puede recurrir al modelo explicativo de Marx y hacer referencia a la "dominación económica de clases que se atrinchera tras la dinámica específica y anónima de un proceso de realización del capital, desconecta- do de toda orientación respecto a valores de uso" ${ }^{\prime 34}$. Es decir, el mecanismo que impulsa la expansión de los sistemas económico y estatal más allá de los límites institucionales funcionales a la reproducción material de las sociedades modernas hacia una penetración en los plexos comunicativos necesarios para la reproducción simbólica del mundo de la vida debe ser comprendido a partir de "la dinámica de los enfrentamientos de clases" ${ }^{\prime 35}$, que impulsaría a la clase dominante a servirse de la dinámica propia de diferenciación de la economía en la sociedad moderna para defender $y$ reforzar sus intereses contra las clases subalternas.

Si bien es cierto que la colonización no es un efecto de la modernización como tal sino del patrón selectivo que ha sido realizado efectivamente en el marco del enfrentamiento de clases característico de las sociedades modernas, para Habermas está claro que es la racionalización del mundo de la vida lo que pone las condiciones para la diferenciación sistémica y su reobrar colonizador sobre el propio mundo de la vida. Esto constituye "la incontenible ironía del proceso histórico universal de Ilustración: la racionalización del mundo de la vida hace posible un aumento de la complejidad sistémica, complejidad que se hipertrofia hasta el punto de que los imperativos sistémicos, ya sin freno alguno, desbordan la capacidad de absorción del mundo de la vida, el cual queda instrumentali- 
zado por ellos." ${ }^{136}$ Esta es la paradoja constitutiva de la modernización: la racionalización del mundo de la vida pone las condiciones para la diferenciación sistémica y su posterior reacción sobre el mundo de la vida en forma de colonización ${ }^{37}$. El hecho de que tal posibilidad se haga efectiva no es algo constitutivo al propio proceso de modernización sino al patrón selectivo que ha seguido la misma a partir del modo en que las clases dominantes en la sociedad capitalista ha utilizado a su favor los imperativos sistémicos del subsistema económico. Cabría pensar, como sostiene Bernstein ${ }^{38}$, en formas alternativas de modernización respecto al modo selectivo efectivamente realizado en el seno de las sociedades desarrolladas. Ahora bien, todas esas modernidades pensables como posibles deben cumplir con ese patrón definidor de la modernidad como tal consistente en el doble proceso de diferenciación de las esferas de validez culturales y de los subsistemas respecto al mundo de la vida y están condenadas a reproducir esa paradoja que le confiere al proceso de modernización social un marcado carácter trágico.

\subsection{Supuestos e implica-} ciones de la opción téorica por las categorías de integración y coordinación sistémicas

A partir de esta breve exposición de la concepción de la modernización social de Habermas, voy a problematizar lo que constituye la base de la misma, a saber la distinción entre dos tipos diferentes de integración de la acción social y entre dos formas de coordinación de la acción que les corresponden, distinción que orienta la reconstrucción histórica que Habermas realiza del proceso de modernización social. Habermas afirma que debe distinguirse "entre los mecanismos de coordinación de la acción que armonizan entre sí las orientaciones de acción de los participantes y aqueIlos otros mecanismos que a través de un entrelazamiento funcional de las consecuencias agregadas de la acción estabilizan plexos de acción no-pretendidos. La integración de un sistema de acción es producida en el primer caso por medio de un consenso asegurado normativamente o alcanzado comunicativamente, $y$, en el segundo, mediante una regulación no-normativa de decisiones particulares que se sitúa allende la conciencia de los actores. La distinción entre una integración social, que se apoya en las propias orientaciones de la acción, y una integración sistémica de la sociedad, es decir, una integración que se cumple asiendo a través de, o atravesando, esas orientaciones de acción nos obliga a introduccir la correspondiente diferenciación en el concepto mismo de sociedad." Por un lado, se puede concebir "la sociedad desde la perspectiva de los sujetos agentes que participan en ella, como mundo de la vida de un grupo social. Por el contrario, desde 
la perspectiva de un no-implicado la sociedad sólo puede ser concebida como un sistema de acciones en el que éstas cobran un valor funcional según sea su contribución al mantenimiento de la integridad o "consistencia» sistémica." ${ }^{\prime 40}$ Resulta a todas luces Ilamativo que una teoría de la acción comunicativa otorgue la misma validez a la coordinación de las orientaciones de la acción a través del acuerdo intersubjetivo (por lo tanto, un modo normativo de coordinación de la acción) y una coordinación efectuada a espaldas de los actores sociales a través del modo en que las consecuencias de las acciones individuales acaban generando "plexos de acción nopretendidos" que resultan funcionales para la reproducción social (por lo tanto, un tipo de coordinación no normativo). La primera es una coordinación intencional, consciente y consensuada de la acción, la segunda es una coordinación no-intencional, inconsciente y no acordada de la acción, efectuada a través del entrelazamiento funcional de las consecuencias no disponibles de las acciones individuales. Que Habermas tiene en mente como modelo de este segundo tipo de coordinación al mecanismo del mercado capitalista es algo sostenido expresamente por él: cuando los integrantes del mundo de la vida "actúan para realizar sus propósitos, sus acciones no solamente quedan coordinadas a través de procesos de entendimiento, sino también a través de nexos funcionales que no son pretendidos y que la mayoría de las veces tampoco resultan perceptibles dentro del horizonte de la vida cotidiana. En las sociedades capitalistas el ejemplo más importante de una regulación no normativa de plexos de cooperación es el mercado. El mercado pertenece a aquellos mecanismos sistémicos que estabilizan plexos de acción no pretendidos mediante un entrelazamiento funcional de las consecuencias de la acción, mientras que el mecanismo del entendimiento armoniza entre sí las orientaciones de acción de los participantes. Por eso he propuesto distinguir entre integración social e integración sistémica: la una se centra en las orientaciones de acción atravesando las cuales opera la otra. En un caso el sistema de acción queda integrado, bien mediante un consenso asegurado normativamente, o bien mediante un consenso comunicativamente alcanzado; en el otro, por medio de un control no normativo de decisiones particulares carentes subjetivamente de coordinación." ${ }^{41}$ La distinción analítica entre integración social y sistémica, justificada a partir de una peculiar teoría de la evolución social, coloca en un mismo nivel de validez lo que desde las posiciones de una teoría de la acción comunicativa no puede ser equiparable en ningún sentido: la coordinación a través del acuerdo intersubjetivo y la coordinación de los trabajos de los productores a través del mercado. La primera es consciente e intencionada, la segunda es un efecto no disponible de acciones realmente no coordinadas 
realizadas por actores solitarios que persiguen fines egoístas. Sostener que "con la diferenciación de la economía" como subsistema autónomo "las acciones se coordinan a través de un medio deslingüistizado como es el dinero" 42 implica, como el mismo Habermas sabe, un uso de la categoría coordinación que no tiene en cuenta la perspectiva del mundo de la vida, pues de cara a la satisfacción de las necesidades fundamentales de la colectividad la coordinación de la acción a través del mercado es realmente una descoordinación, un modo claramente disfuncional para el bien común de la humanidad y para el medio natural de coordinar la acción económica. ¿Cuál perspectiva teórica y política está adoptando Habermas cuando afirma la eficacia del tipo de coordinación de la acción socioeconómica efectuada mediante la relación mercantili ${ }^{43}$ ? ¿Tomando en cuenta la satisfacción de las necesidades de qué grupo social puede sostenerse la idea de esa eficacia? ¿De las necesidades de la humanidad? ¿De los grupos acomodados del primer mundo? En opciones teóricas de este tipo hay incorporada ya la adopción de una determinada perspectiva geo-política que, en el caso de Habermas, le lleva a minusvalorar la realidad del mundo no occidental y centrarse en esa zona del mundo donde la coordinación de la acción social mediante el mercado puede ser valorada más fácilmente sin mala conciencia y sin disonancias cognitivas como eficaz.
Como afirma el mismo Habermas, el carácter de coordinación de la acción del mercado sólo aparece como tal para una perspectiva objetivante, para una posición teórica funcionalista que toma como criterio de validez la efectiva reproducción de los sistemas, en tanto que soportes de las sociedades complejas. Pero para esta perspectiva el criterio no es ya la adecuada satisfacción de las necesidades humanas y el no aniquilamiento del medio natural sino el cumplimiento de los imperativos sistémicos ${ }^{44}$. La concepción habermasiana de la reproducción material del mundo de la vida como conservación de un sistema deja de lado la problemática de la satisfacción de las necesidades colectivas para adoptar la autoconservación sistémica como criterio de validez de la reproducción material de la sociedad. Se ha transitado aquí hacia una visión formalista de la actividad reproductora de la vida que sólo la aprehende a partir de las categorías de la teoría de sistemas, las cuales dejan impensada la cuestión del fin material de la reproducción material de la sociedad, que no puede ser otro que la satisfacción de las necesidades colectivas. La invisibilización de esta dimensión esencial de la reproducción material efectuada por la teoría de sistemas empuja al planteamiento de Habermas sin resistencia hacia una concepción funcionalista de la economía que sólo aprehende crisis sistémicas y no el escándalo cotidiano de la no satisfacción de las necesidades básicas de la inmensa mayoría de la población del planeta ${ }^{45}$. 
Resulta llamativo que un teórico de la racionalidad comunicativa caracterice como parte de "un proceso de aprendizaje evolutivo" la sustitución de la coordinación social por la coordinación funcional de la acción en "el tránsito a las sociedades modernas" ${ }^{\prime 4}$, a pesar de que consiste en la sustitución de la racionalidad comunicativa en la coordinación de las acciones sociales por la coordinación funcional no planificada y no sometida a criterios morales ni a la deliberación colectiva. Está claro que desde la perspectiva de la razón comunicativa el proceso de diferenciación sistémica no puede ser considerado como racional. Sólo desde la perspectiva encarnada por la razón instrumental puede ser valorado como tal. Aquí reside una paradoja central de la teoría habermasiana de la modernización. Hablar de medios de comunicación deslingüistizados que sustituyen al entendimiento lingüístico es algo en sí paradójico y el uso aproblemático de categorías tales sólo puede ser explicado por lo que McCarthy califica como una clara seducción de Habermas por parte de la teoría de sistemas ${ }^{47}$. ¿En qué sentido la reducción del riesgo de disentimiento mediante el uso de un mecanismo de descarga que permite una coordinación deslingüistizada de la acción puede ser un proceso aceptable y no cuestionable por una perspectiva que adopta como normativa la racionalidad comunicativa? Habermas sostiene que con la racionalización del mundo de la vida y la consiguiente tendencia a una reducción de lo aproblemático a partir de la exigencia creciente de entendimiento lingüístico liberado de la tradición religioso-moral, aumenta también la necesidad de interpretación y "el riesgo de disentimiento (potenciado éste ahora por la ejercitación de las capacidades de crítica). Estas sobrecargas y peligros son los que los medios de comunicación [deslingüistizados] se cuidan de absorber." ${ }^{48}$ La cuestión es: ¿a quién interesa que la necesidad creciente de interpretación y discusión y el consecuente aumento del riesgo de disentimiento sean desactivados?, ¿a la sociedad en su conjunto? ¿Desde la perspectiva de quién son la necesidad de interpretación y el riesgo de disentimiento "sobrecargas y peligros"? Desde luego, no para la perspectiva de la inmensa mayoría de la población, sistemáticamente excluida en el proceso de modernización de todo cauce de participación y decisión social y política ${ }^{49}$.

De la distinción entre dos modos de integración deriva Habermas la necesidad de introducir una distinción correspondiente en el concepto mismo de sociedad, apoyándose en la diferenciación referida entre dos perspectivas heterogéneas respecto a la realidad social: para la perspectiva del participante la sociedad aparece como mundo de la vida, mientras que para la perspectiva objetivante del no implicado aparece como sistemas de acción racional con respecto a fines, y es para esta perspectiva que los me- 
canismos funcionales que regulan la acción de los individuos a espaldas de sus intenciones conscientes, careciendo a su vez de carácter normativo (es una regulación más allá del bien y del mal), aparecen como mecanismos de coordinación eficaz. En esta distinción entre dos perspectivas epistemológicas respecto a la realidad social (basadas en una actitud participativa, capaz de comprender las estructuras del mundo de la vida, y en una actitud de observador externo, objetivante, capaz de aprehender las diferenciación de sistemas característica de la modernidad) y su traducción en términos ontológicos como dos niveles distintos de las sociedades modernas cabe comprobar un importante desplazamiento teórico entre la teoría del conocimiento social de Habermas en los años sesenta y su posición posterior. Pues en "La lógica de las ciencias sociales" (1967) había propuesto como metodología adecuada para una sociología crítica una particular síntesis entre comprensión hermenéutica (que adopta la perspectiva del participante en el mundo de la vida que trata de comprender) y teoría funcionalista de la acción (que adopta una perspectiva objetivante propia del no participante) mediada por el psicoanálisis, en tanto que hermenéutica profunda aplicada a las relaciones sociales capaz de poner de manifiesto las distorsiones en la interacción comunicativa generadas estructuralmente. En esta síntesis tanto la hermenéutica como el funcionalismo son mutuamente enfrentados en una contraposición crítica de la que resulta la necesidad de un cuestionamiento de las tendencias ontologizantes e idealistas de la hermenéutica tal como es concebida por Gadamer y una historización del funcionalismo, tanto de sus métodos como de sus resul$\operatorname{tados}^{50}$. Esto todavía tenía alguna consonancia con la concepción de la sociología crítica de Adorno, que no rechazaba el uso de los métodos de la sociología empirista dominante, con la condición de que se historizaran sus métodos y resultados ${ }^{51}$. Del proyecto habermasiano de los años sesenta sólo parece quedar en Teoría de la acción comunicativa los restos de un naufragio. La idea de una síntesis entre las perspectivas comprensiva y funcionalista mediada por su crítica mutua ha sufrido una rekantianización pues, al modo de las antinomias de la razón, en el Habermas posterior ambas perspectivas son consideradas como válidas para el conocimiento de las sociedades modernas, pero incapaces de una mutua contraposición crítica en tanto que se tratan de perspectivas epistémicas heterogéneas. Al no ser posible una síntesis ni una crítica mutua entre ambas perspectivas, el resultado es una deshistorización de las mismas, que en el planteamiento de Habermas (como en las antinomias kantianas) posee relevantes consecuencias ontológicas. Pues de la existencia de tales perspectivas se deriva la postulación de dos dimensiones ontológicas diferentes de la 
realidad social de las sociedades modernas: los sistemas, como dimensiones no-normativas de la realidad social, en las que queda institucionalizada la acción instrumental, y el mundo de la vida, como el ámbito de la sociedad donde la acción moral tiene sus fuentes y es posible. El resultado fundamental del desplazamiento teórico de la teoría habermasiana del conocimiento social es la atribución de una misma validez epistemológica a cada una de las perspectivas referidas, lo cual le permite otorgar igual validez a las realidades u objetividades tematizadas por cada una de ellas. La substantivación de ambas objetividades es fundamentada por Habermas a través de su peculiar teoría de la evolución social de las sociedades modernas. Paradójicamente, tal recurso a una teoría de la evolución social conduce a su planteamiento a una justificación histórico-filosófica de la diferenciación de los subsistemas en una segunda naturaleza que los consagra como realidades constitutivas e insuperables del horizonte histórico moderno. Para Habermas, la diferenciación de los sistemas es un proceso histórico pero los sistemas ya no lo son, pues aparecen ahora como la nueva naturaleza, ya no historizable, de la modernidad: los subsistemas "se coagulan en una segunda naturaleza, en una sociedad vacía de contenido normativo, que nos sale al paso como algo en el mundo objetivo, como un fragmento de vida social objetivizado. El desacoplamiento de sis- tema y mundo de la vida se refleja en el seno de los mundos de la vida modernos, por de pronto, como objetivización: el sistema social rompe definitivamente el horizonte del mundo de la vida, se sustrae a la precomprensión práctica comunicativa cotidiana y sólo resulta ya accesible al saber contraintuitivo de las ciencias sociales que empiezan a emerger desde el siglo XIX"52, es decir, un saber realizado en la perspectiva de una actitud objetivante. De ahí la validez para Habermas de importantes aspectos de la teoría de sistemas de Luhmann: es el instrumento teórico adecuado por su carácter objetivante para analizar y aprehender lo devenido objetivo y como segunda naturaleza en la modernidad. Pero a diferencia de Adorno, Habermas no pretende historizar ni los métodos ni los resultados de la teoría de sistemas, y ello, porque ya ha asumido su propia versión de una tragedia o ironía de la modernización $n^{53}$ : es para afrontar "un proceso de racionalización en contradicción consigo mismo" que Habermas exige "la separación analítica entre integración social e integración sistémica" ${ }^{54}$. Si el histórico devenir una segunda naturaleza de la economía capitalista es un proceso necesario e irreversible, es entonces claramente consecuente la utilización no historizada de la teoría de sistemas. El recurso de esta teoría se enmarca así en un diagnóstico trágico de la modernidad al estilo de Weber, Simmel y el primer Lukács, sólo que, al haber 
dejado atrás el malestar ante lo devenido segunda naturaleza, la teoría de la modernidad de Habermas puede adoptar sin mala conciencia una perspectiva objetivante ante lo reificado de una vez por todas.

\subsection{La modernización como aprendizaje evolutivo occidental y la diversidad de temporalidades modernas}

La concepción de la modernización social por parte de Habermas no es meramente descriptiva, no expone el modo en que efectivamente se han producido en occidente los procesos de racionalización: es normativa. Pues la sociedad moderna encarna un nivel superior de desarrollo en relación a las sociedades premodernas. Este nivel superior viene definido por la propia diferenciación sistémica: son "los subsistemas diferenciados a través de los medios dinero y poder" los que "posibilitan, frente a las sociedades de clases estatalmente organizadas, un nivel más alto de integración y las obligan a una reestructuración (en forma de sociedades de clases económicamente constituidas)." ${ }^{55} \mathrm{El}$ proceso de diferenciación sistémica, que ha impulsado la generación de la sociedad de clases moderna, supone un nivel superior de integración, capaz de responder adecuadamente a las exigencias de reproducción material de las sociedades complejas. Tal proceso de diferenciación, que impulsa "el tránsito a las sociedades modernas", debe ser considerado como "un proceso de aprendizaje evolutivo" ${ }^{\prime 56}$. Por eso la crítica de Marx al capitalismo es a todas luces injustificada, pues "pasa por alto el intrínseco valor evolutivo que poseen los sistemas regidos por medios. No se da cuenta de que la diferenciación del aparato estatal y de la economía representa también un nivel más alto de diferenciación sistémica que abre nuevas posibilidades de control (...). Este nivel de integración tiene una importancia que va más allá de la mera institucionalización de una nueva relación de clases." ${ }^{57}$ En otras palabras, "en el sistema económico capitalista" no hay que ver "solamente una nueva formación de relaciones de clases, sino también un avanzado nivel de diferenciación sistémica con derecho propio." ${ }^{\prime 58} \mathrm{Si}$ "el sistema económico capitalista" no consiste en una mera relación de poder entre clases sino "un subsistema emancipado de contextos normativos", "un fragmento de socialidad exenta de contenido normativo" ${ }^{59}$, entonces la teoría de la modernidad de Habermas puede postular sin mala conciencia como patrón de todo proceso posible de modernización tal diferenciación sistémica: "toda sociedad moderna, cualquiera sea su estructura de clases, tiene que ofrecer un algo grado de diferenciación estructural." ${ }^{\prime 60}$

Habermas está tomando como referente para su modelo normativo de modernización social un tipo específico de evolución histórica geográfica, económica y culturalmente 
ubicables $^{61}$. En cambio, debería reconocer la profunda limitación de su teoría de la modernización, pues él mismo confiesa qué camino ha seguido su investigación: "he estudiado las condiciones de partida de la modernización analizando el caso de este tipo de sociedades [las sociedades en las que se implanta el capitalismo burgués] y he seguido la senda evolutiva capitalista." ${ }^{\prime 2}$ El proceso de autonomización de la economía capitalista como un subsistema exento de contenido normativo que define a las sociedades europeo-occidentales da la norma para la comprensión de la esencia de la modernidad y da el criterio para enjuiciar cuándo una sociedad todavía no moderna ha tomado la anhelada vía de la modernización. Aquí encontramos un modelo normativo evolutivo con resonancias hegelianas, a partir del cual cabe distinguir entre una zona del globo en la que la modernización ha alcanzado ya exitosa plasmación y una periferia todavía en camino que debe tomar como norte de su aprendizaje evolutivo el tipo de sociedades plasmado en el centro de la economía-mundo ${ }^{63}$. Y esto tiene claras implicaciones en cuanto a la concepción y experiencia del tiempo, pues si para los países periféricos en vías de modernización la temporalidad sigue siendo patentemente lineal y orientada a una meta respecto a la que cabe una aproximación progresiva a través de una serie bien específica de transformaciones económico-sociales, no resulta clara qué temporalidad correspondería a las sociedades del centro en las que la modernización, como diferenciación, de una vez por todas, de los subsistemas, ha alcanzado exitoso cumplimiento. ¿Qué transformaciones cualitativas es capaz de pensar la teoría de la modernidad de Habermas para los países ya modernizados? Como afirma adecuadamente Ignacio Sotelo, "desde el análisis sistémico que hace suyo Habermas se cierran las puertas a cualquier horizonte distinto del que impone la colonización progresiva del mundo de la vida por el sistema." ${ }^{64}$ En sociedades donde las transformaciones que definen el curso evolutivo moderno están ya plenamente realizadas e institucionalizadas y donde las estructuras generadas se reconocen como no desdiferenciables, la única temporalidad pensable es la definida por el juego de tensiones entre los sistemas, cuya dinámica bajo el capitalismo (¿y bajo qué otro tipo de sociedad sería pensable la diferenciación de la economía de mercado como sistema?) conduce a la colonización del espacio social que requiere de reproducción simbólicodiscursiva, y el mundo de la vida, obligado a una continua resistencia frente a la hybris sistémica y a un esfuerzo continuo por reinstalar a los sistemas dentro de sus propios y justos límites. Habermas afirma que "el carácter desgarrado de la modernización social" se sostiene en el "entreveramiento y pugna de imperativos sistémicos e imperati- 
vos del mundo de la vida"65. Esta pugna no es solventable. El desgarramiento constitutivo de la modernidad conduce necesariamente a la emergencia de "nuevas superficies de rozamiento entre imperativos sistémicos e imperativos del mundo de la vida", donde "se producen conflictos que no pueden ser absorbidos por las vigentes estructuras de compromiso." ${ }^{\prime 66}$ Este irrebasable "conflicto de límites" consustancial a la modernidad define para Habermas "la necesidad de un nuevo trazado de límites entre sistema y mundo de la vida" a partir de un Ilamado ciertamente abstracto a "la fuerza de integración social que la solidaridad posee", la cual "debería poder afirmarse contra los medios de control "dinero»y "poder»" ${ }^{\prime \prime}$. Desde los parámetros de la teoría de Habermas debe sostenerse que las sociedades de la modernidad realizada (que para Jameson son

Notas

1 F. Nietzsche, Werke. Kritische Studienausgabe, edición de G. Colli y M. Montinari, Walter de Gruyter, Berlin/ New York, 1988, vol. 9, p. 523, $11[202]$.

2 F. Nietzsche, op. cit., p. 500, $11[152]$.

3 W. Benjamin, Libro de los Pasajes, Akal, Madrid, 2005, p. 838-9.

4 G.W.F. Hegel, Principios de la filosofía del derecho, Edhasa, Barcelona, 19992 (=PFD), \$206, Obs., p. 325. el referente social de la pregonada postmodernidad ${ }^{68}$ ) viven en una temporalidad incapaz de generar novedad cualitativa alguna más allá del incesante retorno de la misma situación de antagonismo y confrontación, constitutiva a la modernidad, entre los imperativos de los sistemas y del mundo de la vida: a este conflicto, insolventable y eternamente retornante, sólo cabe ponerle límites. Las sociedades occidentales actuales, que se perciben como las posiciones históricamente avanzadas de un proceso de aprendizaje evolutivo progresivo, normativo para los demás países, viven sin embargo en un tiempo agotado que ya ha realizado lo pensable de una vez por todas como posible. Aquí es donde la visión descarnada de la modernidad de Benjamin tiene algo que decir: “¿Cómo es eso? ¿Un mundo que se hunde en la rigidez de la muerte habla de progreso?"69 


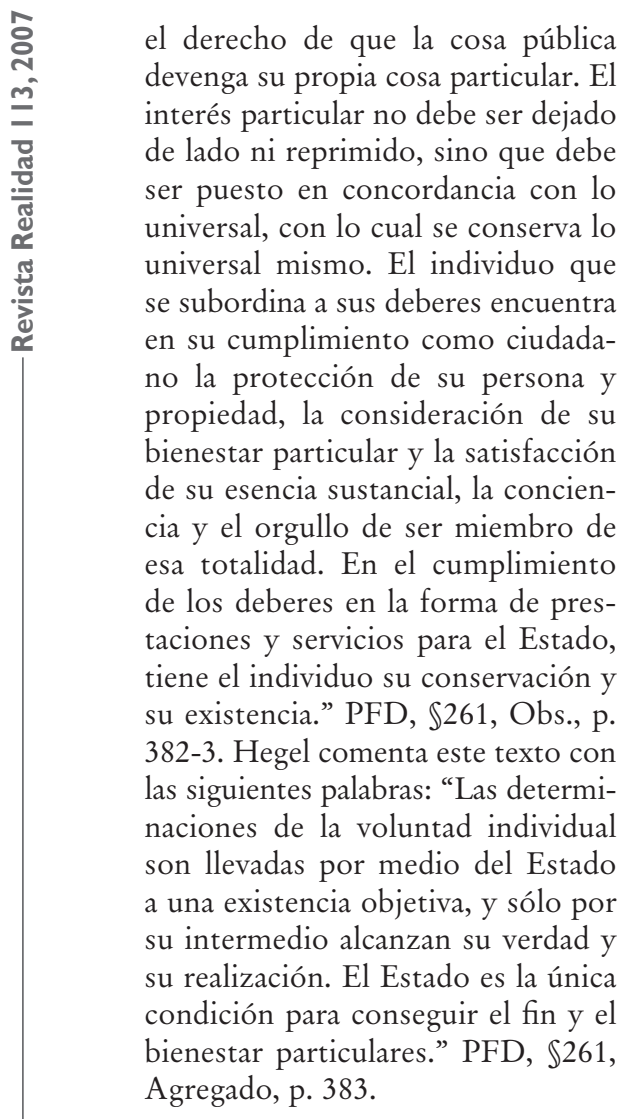

13 PFD, \$290, Agregado, p. 440-1. Sobre el papel mediador de la corporación en el tránsito de la sociedad civil al Estado, ver F. Prieto, El pensamiento político de Hegel, Universidad Pontificia Comillas, Madrid, 1983, p. 186-8.

14 PFD, $\$ 260$, p. 379.

15 PFD, $\$ 260$, p. 380.

16 PFD, \$246, p. 361 y $\$ 248$, p. 362.

17 PFD, $\$ 333$, p. 485.

18 El "momento ético de la guerra" consiste en que muestra la contingencia y la transitoriedad de los bienes ("posesión y vida”), es decir, "es la situación en la que se toma en serio la vanidad de los bienes y de las cosas temporales". De esta manera, la guerra mantiene "la salud ética de los pueblos”, librándoles de los vicios provocados por una paz prolongada en la que "las particularidades se vuelven cada vez más sólidas y osificadas”; ver PFD, \$324, p. 476-8.

19 PFD, \$324, Agregado, p. 478-9.

20 La detención de la temporalidad histórica afectaría también a los países periféricos integrados a los mercados de las metrópolis. El tiempo progresivo no perviviría en ellos frente a un centro que ya ha desarrollado la modernidad, pues los países del centro exportan la escisión entre riqueza desproporcionada $y$ pobreza crónica desde su interior a su relación con las regiones del globo que incorpora como nuevos mercados, pues los pueblos periféricos son expropiados de su riqueza por una forma de intercambio desigual mantenido violentamente por una política comercial y militar que impide el desarrollo industrial de la periferia. El intercambio con la metrópoli acrecienta la desigualdad: la periferia no experimenta la temporalidad ni siquiera como retorno de lo igual sino como condena que impone paulatina e implacablemente el propio hundimiento.

21 Este proceso es expuesto por Habermas en diversos lugares: "La modernidad: un proyecto inacabado", en J. Habermas, Ensayos políticos, Península, Barcelona, 19973, p. 265-283; Teoría de la acción comunicativa, Taurus, Madrid, 1987 (=TAC), vol. I, p. 286-316; El discurso filosófico de la modernidad, Taurus, Madrid, 1989, p. 11-35. 
22 Una síntesis de este proceso es presentada en J. Habermas, Teoría de la acción comunicativa: complementos y estudios previos, Cátedra, Madrid, 1989, p. 471-5 y El discurso filosófico de la modernidad, ed. cit., p. 411-422. Ver además la clarificadora exposición de Th. McCarthy, La teoría crítica de Jürgen Habermas, Tecnos, Madrid, 1987, p. 464-479.

23 Cf. el prefacio de 1990 de Habermas a la nueva edición de su obra Historia y crítica de la opinión pública, Gustavo Gili, Barcelona, 1995, p. 23 ss.

24 TAC II, p. 409.

25 Este paso en la argumentación de Habermas es clarificadoramente expuesto en A. Wellmer, "Razón, utopía y dialéctica de la Ilustración” en VV.AA., Habermas y la modernidad, Cátedra, Madrid, 1999, p. 92 ss.

26 TAC II, p. 255.

27 TAC II, p. 433.

28 TAC II, p. 455.

29 TAC II, p. 280.

30 TAC II, p. 465.

31 TAC II, p. 469.

32 TAC II, p. 402.

33 TAC II, p. 464.

34 TAC II, p. 465-6.

35 TAC II, p. 469.

36 TAC II, p. 219. Ver también TAC II, p. 263. Sobre la concepción de la modernización de Habermas como un proceso constitutivamente paradójico ver J. Lorenzo Tomé, Las identidades. Las identidades morales y políticas en la obra de Jürgen $\mathrm{Ha}$ bermas, Biblioteca Nueva, Madrid, 2004, p. 58 ss.
37 La paradoja de la modernidad puede ser formulada en términos aún más dramáticos: "a medida que la base de validez de la acción orientada al entendimiento sustituye a los fundamentos sacros de la integración social, se produce la anticipación (sugerida por las propias estructuras del mundo de la vida y, por así decirlo, trascendental, que determina y a la vez sobrepasa a la ideología burguesa) de una comunicación cotidiana postradicional capaz de conservar su autonomía, de poner coto a la dinámica propia de los subsistemas autonomizados (...) y de escapar a los peligros combinados que representan la cosificación y la desertización cultural del mundo de la vida.” De esta manera, "paradójicamente, la racionalización del mundo de la vida permite ambas cosas a la par: la cosificación sistémicamente inducida y la proyección de una perspectiva utópica" que posibilita criticar a la modernidación realmente existente; ver TAC II, p. 467.

38 Ver R. Bernstein, "Introducción”, en VV.AA., Habermas y la modernidad, ed. cit., p. 45 y ss.

39 TAC II, p. 167.

40 Ibíd.

41 TAC II, p. 213.

42 TAC II, p. 251.

43 Habermas sostiene que "el medio «dinero» (...) se ha desgajado del lenguaje normal como un código especial cortado al talle de situaciones estándar (las situaciones de intercambio), que por llevar inserta una estructura de preferencias (relativas a oferta y demanda) puede coordinar con eficacia decisiones de acción, sin tener que hacer uso de los recursos 


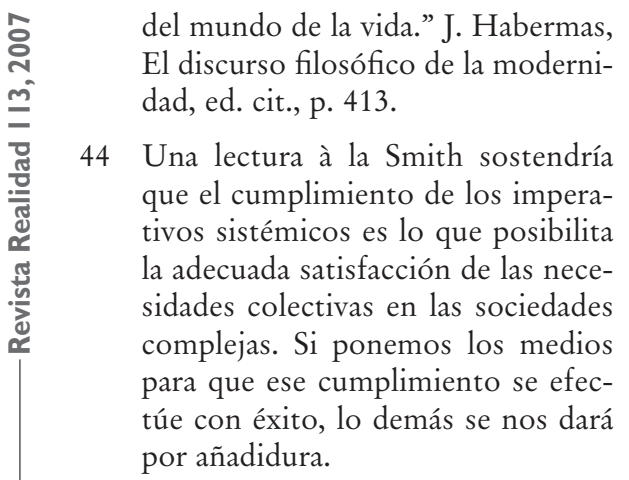

45 Es mérito de Franz Hinkelammert el haber opuesto al formalismo funcionalista de determinadas teorías sociales y económicas contemporáneas el principio material de la reproducción de la vida común como criterio normativo para evaluar críticamente tanto las prácticas políticas concretas como las teorías sobre las que se sustentan. Ver F. Hinkelammert, Crítica de la razón utópica, Desclée de Brouwer, Bilbao, 2002. La introducción de este principio orienta en buena medida la polémica de E. Dussel contra Apel y Habermas; ver, por ejemplo, E. Dussel, Hacia una filosofía política crítica, Desclée de Brouwer, Bilbao, 2001, p. 43-64.

46 TAC II, p. 447.

47 Ver el capítulo titulado "Complejidad y democracia: las seducciones de la teoría de sistemas" del libro de Th. McCarthy Ideales e ilusiones, Tecnos, Madrid, 1992, p. 165-192. La seducción de la que habla McCarthy conduce a Habermas a formulaciones como ésta: "la empresa capitalista y la administración moderna son unidades sistémicamente autonomizadas en el seno de los subsistemas exentos de contenido normativo. Las organizaciones convertidas así en autónomas se caracterizan principalmente, como el propio Luhmann subraya, por su capacidad de independizarse (...) de los contextos comunicativamente estructurados del mundo de la vida, de las orientaciones valorativas concretas y de las concretas disposiciones de la acción (...) de las personas que las componen, las cuales se ven así desplazadas y convertidas en entornos de la organización.” TAC II, p. 244.

48 TAC II, p. 258.

49 El modo en que Habermas asume una perspectiva sistémica en su concepción de la emergencia de la sociedad moderna se pone de manifiesto en lugares como éste: "Los subsistemas sociales que se diferencian a través de tales medios [de control, como el dinero y el poder] pueden independizarse frente a un mundo de la vida reducido ahora a entorno del sistema. De ahí que desde la perspectiva del mundo de la vida este asentamiento de la acción sobre medios de control aparezca (...) como un alivio de la necesidad de comunicación y una reducción de los riesgos que la comunicación comporta.” (TAC II, p. 259). ¿Puede creerse realmente que para la perspectiva del mundo de la vida el ser descargada de la necesidad de comunicación y del riesgo de disentimiento puede ser experimentado como un alivio y no, en cambio, como una amenaza, como un peligro para su consistencia y continuidad?

50 Ver J. Habermas, La lógica de las ciencias sociales, Tecnos, Madrid, 1990.

51 Ver Th. W. Adorno, Escritos sociológicos I, Akal, Madrid, 2004.

52 TAC II, p. 244. 
53 A. Honneth ha sostenido que la teoría de la modernización de $\mathrm{Ha}$ bermas puede ser considerada como una peculiar versión, en el marco de una teoría de la comunicación, de la Dialéctica de la Ilustración tematizada por Adorno y Horkheimer; ver A. Honneth, Kritik der Macht, Suhrkamp, Frankfurt am Main, 1989, p. 307-334. Comparte este parecer J.A. Estrada, Por una ética sin teología. Habermas como filósofo de la religión, Trotta, Madrid, 2004, p. 125-7.

54 TAC II, p. 427.

55 TAC II, p. 433.

56 TAC II, p. 447.

57 TAC II, p. 480.

58 TAC II, p. 528.

59 TAC II, p. 241-2.

60 TAC II, p. 481. Se ha sostenido que para Habermas "el fenómeno que caracteriza a la modernidad, y de modo creciente a la sociedad contemporánea, hasta el punto de que sirve para definirla, es que el sistema se va desenganchando del mundo de la vida"; I. Sotelo, "El pensamiento político de Jürgen Habermas", en J.A. Gimbernat (ed.), La filosofía moral y política de Jürgen Habermas, Biblioteca Nueva, Madrid, 1997, p. 191.

61 Consecuentemente, para O. Kozlarek la posición de Habermas "pone de manifiesto un problema esencial: el cosmopolitismo abstracto en el momento de concretizar tiende siempre a absolutizar lo particular de lo propio.” O. Kozlarek, Crítica, acción y modernidad. Hacia una conciencia del mundo, Editorial Dríada/Universidad Michoacana de San Nicolás de Hidalgo, México,
2004, p. 233. R. Fornet-Betancourt ha cuestionado también el eurocentrismo tanto de la primera como de la segunda generación de la Escuela de Francfort; ver el capítulo titulado “Teoría Crítica, liberación y diálogo intercultural" de su obra Transformación intercultural de la filosofía, Desclée de Brouwer, Bilbao, 2001, p. 273-284.

62 TAC II, p. 542.

63 J.M. Mardones ha criticado la concepción de Habermas de la evolución social de occidente como paradigmática; ver su obra Razón comunicativa y teoría crítica, Universidad del País Vasco, Bilbao, 1985, p. 300-1. El horizonte claramente eurocéntrico del pensamiento de Habermas se pone de manifiesto en la pregunta con la que cierra sus conferencias sobre el discurso filosófico moderno: "¿quién otro sino Europa podría sacar de sus propias tradiciones la penetración, la energía, la voluntad de visión y fantasía -todo aquello que sería menester para quitar su fuerza configuradora de mentalidades a las premisas, desde hace ya mucho tiempo no metafísicas sino metabiológicas, de esta enceguecida compulsión a mantener y seguir expandiendo el sistema?”, J. Habermas, El discurso filosófico de la modernidad, ed. cit., p. 433.

64 I. Sotelo, "El pensamiento político de Jürgen Habermas”, en J.A. Gimbernat (ed.), op. cit., p. 192.

65 J. Habermas, El discurso filosófico de la modernidad, ed. cit., p. 419.

66 Op. cit., p. 421.

67 Op. cit., p. 422, 429-431.

68 Ver F. Jameson, Teoría de la postmodernidad, Trotta, Madrid, 1996.

69 W. Benjamin, El Libro de los Pasajes, ed. cit., p. 341. 